Title: A Co-Curricular Diabetes-Specific Elective with Interprofessional Students and Faculty

\author{
Authors: \\ Mohammad Fazel, PharmD \\ College of Medicine - Tucson; The University of Arizona \\ 1501 N. Campbell Ave. \\ Tucson, AZ 85724 \\ Phone: $520-820-2869$ \\ Email: morox5@email.arizona.edu
}

Janet Cooley, PharmD, BCACP

College of Pharmacy; The University of Arizona

1295 N. Martin Ave.

Tucson, Arizona 85721-0202

Office: $520-626-5095$

Email: cooley@pharmacy.arizona.edu

Sawsan Kurdi, PharmD

College of Pharmacy; The University of Arizona

1295 N. Martin Ave.

Tucson, Arizona 85721-0202

Mobile: 617-291-2567

Email: kurdi@pharmacy.arizona.edu

Maryam Fazel, PharmD, BCPS, BCACP, CDE

College of Pharmacy and College of Medicine - Tucson; The University of Arizona

1295 N. Martin Ave.

Tucson, Arizona 85721-0202

Office: $520-626-4291$

Email: maryamfazel@pharmacy.arizona.edu 
Corresponding Author:

Janet Cooley, PharmD, BCACP

College of Pharmacy; The University of Arizona

1295 N. Martin Ave.

Tucson, Arizona 85721-0202

Office: 520-626-5095

Fax: 520-626-7355

Email: cooley@pharmacy.arizona.edu 


\begin{abstract}
Background and Purpose: To develop and assess the effectiveness of an interprofessional co-curricular elective in improving pharmacy students' confidence in providing diabetes self-management education and support (DSMES) to patients.
\end{abstract}

Educational Activity and Setting: In a collaboration between the colleges of medicine and pharmacy, a student -organized diabetes-specific enrichment elective, which was originally only offered to medical students, was extended to include to pharmacy students. The interprofessional elective consisted of an overview of diabetes and its prevention, medications, insulin therapy/administration, blood glucose monitoring, insulin pumps, nutrition and fitness. This elective served as a co-curricular activity, in that it was not offered for course credits, but rather provided an opportunity to learn in an interprofessional environment contact small group, unstructured interactions. The impact of the elective on pharmacy student confidence was evaluated using a retrospective pre-post survey.

Findings: A total of 16 pharmacy students participated. The survey response rate was about $63 \%$ (10/16). A Wilcoxon signed-rank test revealed an increase in students' confidence in the following areas: assessing patients' understanding of diabetes, discussing the monitoring and managing of blood glucose, lifestyle modifications, diabetes self-management, and basics of insulin pump therapy with patients. No statistically significant increase was detected in the area of talking to patients about diabetes. Eighty percent of the respondents found the elective valuable.

Discussion: The unstructured interprofessional learning environment gave pharmacy and medical students the opportunity to hear one another's questions, observe different thought processes, and communicate naturally in a setting similar to real life situations. The interprofessional learning environment was further enhanced through the modeling of interprofessional interactions and knowledge exchange among course instructors.

Summary: An interprofessional co-curricular diabetes-specific elective significantly improved pharmacy students' confidence in providing DMSES to patients in the majority of assessed areas. Pharmacy and medical students were given the opportunity to learn alongside one another and learn from an interprofessional team of instructors in a setting that modeled communication and collaboration. Developing such enrichment electives may be beneficial to equip pharmacy students with the skills 
needed to provide education/support to patients with chronic diseases and interact with other health professionals effectively.

Key words: Diabetes, self-management, pharmacy students, interprofessional, education Abbreviations: DMSES (diabetes self-management education and support)

\section{Conflict of Interest and Financial Disclosures:}

The authors have no conflict of interest or financial interest to disclose.

The author, Mohammad Fazel is the son of the author Maryam T Fazel. This has not affected this work.

\section{Specific Contribution to Literature:}

This paper provides information on developing and assessing a co-curricular, student started, diseasespecific elective in a unique interprofessional learning setting. This experience included an interprofessional team of instructors as well as collaboration between colleges of medicine and pharmacy. The paper provides information and ideas for faculty and students interested in similar opportunities to establish such optional courses, which are aligned with Accreditation Council for Pharmacy Education (ACPE) Standards two and three as related to pharmacy practice and patient care, Standard 11 as related to interprofessional education and Standard 25 as related to co-curricular activities. 


\section{Background and Purpose}

The diabetes mellitus pandemic is a global health emergency with high and increasing prevalence, currently affecting about 415 million individuals worldwide. ${ }^{1}$ Within the United States (U.S.) diabetes afflicts 30.2 million people with an estimated incidence of 1.5 million newly diagnosed cases among adults in 2015 . 2 Diabetes is associated with devastating complications (cardiovascular, ophthalmologic, renal, and neurologic) and significant economic burden on individuals and health systems. ${ }^{1}$ Treatment of diabetes or its complications is costly and accounted for an estimated health expenditure of 320 billion dollars in the U.S. during 2015. ${ }^{1,3}$ Effective diabetes management and optimization of glycemic control are critical for preventing or delaying the associated complications. ${ }^{4-7}$

Diabetes self-management is a crucial component of controlling this chronic disease and includes lifestyle and behavioral modifications, problem solving and self-care decision-making. ${ }^{8}$ Diabetes selfmanagement education and support (DSMES) provides patients with the knowledge, skills and tools to enhance self-management decision-making and has been shown to be associated with better diabetes selfcare related behaviors. ${ }^{8-11}$ Furthermore, DSMES has been linked to lower A1C, improved quality of life and lower healthcare costs. ${ }^{10,12-14}$

Pharmacists are poised to provide DSMES to patients in different healthcare settings. Various modalities have been used to train pharmacy students on providing DSMES and have been associated with improved pharmacy student confidence in providing such education and support. These uniprofessional modalities include pharmacy students observing pharmacy faculty teaching a DSMES class, an elective course which included a simulation experience, combination of diabetes related lectures/home glucose monitoring assignments/active learning workshops, and lectures. Additionally, hands-on training sessions were provided. ${ }^{15-18}$

Programs that improve knowledge, abilities, and skills in providing patient-centered care, including educating individuals/communities on chronic disease management, are aligned with Accreditation Council for Pharmacy Education (ACPE) Standards two and three relating to pharmacy practice and patient care.

19 Additionally, colleges of pharmacy are also exploring programs that fulfill ACPE Standard 11 as it relates to the incorporation of interprofessional education into the pharmacy curriculum and Standard 25 as it relates to the assessment of co-curricular activities. ${ }^{19}$ 
Through collaboration between College of Medicine and College of Pharmacy, a diabetes-specific elective with interprofessional instruction that was previously provided solely to medical students became available to pharmacy students. This course was originally developed and organized by a group of medical students that determined the content to include in the course with the help of two faculty advisors (an endocrinologist and a pharmacist specialized in diabetes care). The goal of this partnership between the two colleges was to expand the training and education provided within the elective to a greater number of students, along with developing an interprofessional learning environment where medical and pharmacy students learn alongside one another. This elective served as a disease specific co-curricular activity, in that students volunteered to participate and were not given course credit, and were provided with the opportunity for interprofessional contact. Interprofessional interactions within this elective were not structured through pre-designed activities. The efficacy of the elective was evaluated using survey results regarding changes in pharmacy students' confidence in providing DSMES to patients with diabetes. This casual environment allowed pharmacy and medical students the opportunity to have interactions similar to those, which occur in a professional setting on rounds or in clinic. In addition, the interprofessional team of course instructors modeled effective teamwork and exchange of knowledge throughout the elective. The purpose of this paper is to provide information that can be used for the development and assessment of similar co-curricular elective courses that promote patient care, team communication and contact between various health professions that meet ACPE Standards two, three, 11 and $25 .{ }^{19}$

\section{Educational Activity and Setting}

The College of Medicine at a public university in the southwestern United States provides medical students with the opportunity to obtain supplemental knowledge in various areas of interest by enrolling in optional enrichment electives. A group of medical students implemented and coordinated the formation of the Diabetes Education, Prevention, and Outreach (DEPO) Commitment to Underserved People (CUP), a community service organization within the College of Medicine. The DEPO CUP program established a pre-clerkship diabetes-specific enrichment elective that was first offered in the fall of 2015. The DEPO CUP program faculty advisors consisted of a pharmacist specialized in diabetes-care and an endocrinologist. Details of the steps taken in establishing this elective can be accessed in a previous publication. ${ }^{20}$ 
In the second year of offering this elective, the DEPO CUP program coordinators worked with the associated College of Pharmacy to form a partnership in which pharmacy students in the $2^{\text {nd }}$ and $3^{\text {rd }}$ year of their professional education (P2 and P3) could also participate in the elective.

The determination was made, based on anticipated number of enrolled medical students and limitations of space within the classroom, to offer this class to fifteen P2 and P3 students on a first-come first-serve basis. An email was sent to the students' listserv with a one-week deadline. A total of sixteen pharmacy students showed interest and were enrolled.

As was detailed in a previous publication, the topics covered within the Diabetes Enrichment Elective were put in place and remained consistent over the two-year history of this course, based on the curriculum suggested for successful DSMES by the American Diabetes Association (ADA) DSMES National Standards. 9,20 The topics suggested by Standard 6 of these standards included: education regarding healthy eating, medications, understanding the disease, being physically active, prevention, and blood glucose self-monitoring. As a result, the Diabetes Enrichment Elective consisted of seven one-hour sessions focused on the stated topics. The course highlighted aspects of insulin pump therapy, along with providing students with hands-on experience with regards to proper insulin injection technique/mixing. Additionally, students learned about blood glucose monitoring and had the opportunity to become familiar with insulin pens and pumps. The course consisted of an interprofessional group of instructors with expertise in the field of diabetes care, which included a pharmacist, dietitian, nurse, and endocrinologists. The elective schedule included a total of seven sessions (overview of diabetes, diabetes prevention, diabetes and fitness/exercise, overview of diabetes medications, proper insulin injection and blood glucose self-monitoring, insulin pump therapy overview, and diabetes nutrition) with one session provided per week of elective..

The learning objectives included improving students' confidence in providing DSMES to patients by assessing the patients' understanding of the disease and discussing the disease process, monitoring and managing blood glucose, life-style modifications, insulin pump therapy, and diabetes self-management support. The process was focused on familiarizing the students to the DSMES topics and assessing their self-reported confidence level. 
Following completion of the course, an optional and anonymous survey was emailed to the P2 and P3 students enrolled in this course. This retrospective pre-post survey consisted of a six-item Likert-style questionnaire as well as questions to collect demographic data such as sex and year of pharmacy school. The intent of the survey was to evaluate student perception with regards to whether the learning objectives were achieved and if pharmacy students found the experience valuable/would advise their colleagues to attend the course in the future. Wilcoxon signed-rank and descriptive analyses were utilized to assess the results of the survey. The affiliated Institutional Review Board approved this study.

In addition, the course provided students with an interprofessional learning environment with an interprofessional group of course instructors who modeled knowledge exchange and interprofessional teamwork.

\section{Findings}

Sixteen pharmacy students (six P2 and 10 P3 students) enrolled in and joined 24 medical students in the elective. The survey response rate was approximately $63 \%(10 / 16)$. The survey respondents included $60 \%(6 / 10)$ female and $40 \%(4 / 10)$ male. The respondents consisted of $30 \%(3 / 10)$ second year and $70 \%$ $(7 / 10)$ third year pharmacy students. All survey participants attended three or more sessions of the Diabetes Enrichment Elective.

The results of the retrospective pre-post survey were analyzed to compare students' confidence level in providing various areas of DSMES before and after participation in the elective. The six assessed areas included confidence in evaluating patients' knowledge of diabetes, talking with patients about monitoring and managing blood glucose, lifestyle modification, diabetes self-management, and basics of insulin pump therapy.

A Wilcoxon signed-rank was used to analyze the survey results. The analysis showed a statistically significant increase in students' confidence in five out of the six assessed areas after participating in the Diabetes Enrichment Elective, $P<0.05$ with a large effect size $(r>0.5)$ (Table 1). The area that did not show a statistically significant increase included confidence in talking to patients about diabetes, $\mathrm{P}=0.063$ with large effect size ( $r=0.67)$. SPSS version 24 (IBM Corporation, Armonk, NY, USA) was used for the statistical analyses. 
Regarding course satisfaction, $80 \%(8 / 10)$ of survey respondents found the Diabetes Enrichment Elective valuable and indicated that they would recommend it to their colleagues.

Several pertinent observations were made throughout the course of the elective with respect to the interprofessional learning environment and student interactions. Students were able to interact naturally and develop effective communication. Pharmacy students often asked questions during didactic portions of the elective regarding how to best care for and educate patients that may not have occurred to the medical students based on their specific perspective/experiences and vice versa. In addition, during hands on training sessions, medical and pharmacy students often worked well together and were able to learn alongside one other in this interprofessional setting. Also, as stated above, the course instructors modeled effective interprofessional knowledge exchange and teamwork. It is believed by the authors that this modeling served as an instrumental factor in facilitating natural and effective interaction between students across professional lines.

\section{Discussion}

The interprofessional diabetes-specific elective was well received by pharmacy students. This elective offered students the opportunity to develop/enhance their skills in diabetes prevention, medications, bloodglucose monitoring, insulin injection techniques, insulin pumps, nutrition and fitness. As demonstrated by the gathered results, students demonstrated increased confidence in multiple areas. Additionally, students responded positively to the training with the majority of respondents noting that they would recommend this elective to their colleagues. These results are similar to those seen in medical students who previously participated in this elective. ${ }^{20}$

The one item that did not show a statistically significant increase was the students' confidence in talking with patients about diabetes. ${ }^{20}$ This finding was inconsistent with previous findings in medical student surveys. It is noted that more pharmacy students reported to be highly or very highly confident in this area pre-participation in the elective when compared to the medical students surveyed previously, $7 / 10$ $(70 \%)$ versus $1 / 8(0.13 \%)$ respectively. ${ }^{21}$ One possible explanation may be that the pharmacy student participants were second and third year students versus medical students who were in their first or second year of professional education. As a result, medical students were more likely to start with low confidence and experience, which enabled significant improvement in confidence through involvement in this elective. 
In contrast, the academically more advances pharmacy student cohort was more likely to begin with more confidence, leading to difficulty in demonstrating improvement through post-participation survey results. One way to address this concern and strengthen this area in future iterations of this elective could be to incorporate an experiential education component in which students participate in a diabetes education session with real life patients or participate in role play activities with their fellow students.

Trainings such as this offer students an opportunity to better prepare themselves for clerkships and related patient care activities. This enrichment elective and similar trainings allow students to explore their interests and to begin specializing in an area before their advanced pharmacy practice experiences (APPEs).

The interprofessional learning opportunity provided by this course allowed pharmacy and medical students to interact and learn together in early stages of their professional development. The benefit of this early introduction of an interprofessional learning environment was to enable interactions between medical and pharmacy students to set a framework for their interactions later on in their careers. As stated above, observations suggested that students were able to learn alongside one another and hear/observe different thought processes and questions regarding how to best interact clinically with patients with diabetes. In addition, the interprofessional team of instructors modeled effective interprofessional teamwork and knowledge sharing throughout the elective. To improve shared learning, future considerations will be to provide a questionnaire to assess students' perception of interprofessional interactions and teamwork during the elective. In doing so, it can be determined if incorporation of structured activities focusing on the interprofessional interactions could enhance teamwork or if students prefer the current naturally occurring interactions. This questionnaire should also address and assess the interprofessional education principals and competencies as outlined by the Interprofessional Education Collaborative (IPEC) and World Health Organization (WHO). ${ }^{21,22}$ Additionally, as the elective is currently co-taught by an interprofessional team of educators to an interprofessional group of students, it provides a great opportunity for further integrating interprofessional learning components into the course. This will aid the professional development of collaborative-practice ready healthcare professionals. Such components could include development of case-based activities that place students in a position to model/practice effective interprofessional interactions and role-playing in various scenarios including the inpatient and outpatient settings. Following 
such activities, students and instructors could take time to reflect and discuss roles and responsibilities of different professions, where interactions were effective, and where improvements could be made. Finally, it would be valuable to evaluate the effect of the program on the students' behaviors and perceptions toward other health care professions.

Wongwiwatthananukit et al. (2013) provides an excellent example of a uni-professional diabetes training program that assesses student competence with an exam and the students gained $100 \%$ competence after completion of the course. ${ }^{18}$ Future directions for this program may include the incorporation of a skills assessment upon completion of the course.

One limitation of the study is the small sample size. This is because the elective is only offered to a small number of students. Furthermore, the survey response rate of $60 \%$ may be a source of bias as the respondents may differ from the non-respondents in terms of their perception of the elective. As students self-select for this type of program, it is difficult to assume that they are a representative group of all the pharmacy students in their cohort. Additionally, this elective is offered as a co-curricular activity, in that students are not offered curricular credit. Therefore, the students who choose to participate are generally high achievers. Also, the survey used in this program has not been formally validated. Furthermore, it would be of value to assess the impact of interprofessional interactions on the effectiveness of the class and this should be considered in future studies.

\section{Summary}

The interprofessional diabetes-specific elective taught by an interprofessional team of instructors enhanced pharmacy students' confidence in offering DSMES to patients with diabetes in the majority of the assessed areas and most students found the course valuable. In addition, students were able to learn alongside one another in an interprofessional setting which provided them with the opportunity to hear and observe different questions and thought processes across professional lines. The interprofessional team of instructors modeled effective teamwork and knowledge exchange throughout the duration of the elective and the course was designed to highlight such teamwork. In an effort to assess students' perception of their respective interprofessional interactions during the course of the elective and the impact on advancing interprofessional competency domains, future considerations will include completing a questionnaire on the interprofessional components of the elective. 


\section{References}

1. International diabetes federation. IDF diabetes atlas, $7 \mathrm{ed}$. brussels, belgium: International diabetes federation, 2015. International Diabetes Federation Web site. http://www. idf.org/diabetesatlas. Updated 2015. Accessed 5/11, 2017.

2. Centers for Disease Control and Prevention. National diabetes statistics report, 2017. https://www.cdc.gov/diabetes/data/statistics/statistics-report.html. Updated 2017. Accessed August 5, 2017.

3. American Diabetes Association. Economic costs of diabetes in the U.S. in 2012. Diabetes Care. 2013;36(4):1033-1046.

4. The effect of intensive treatment of diabetes on the development and progression of long-term complications in insulin-dependent diabetes mellitus. the diabetes control and complications trial research group. N Engl J Med. 1993;329(14):977-986.

5. Intensive blood-glucose control with sulphonylureas or insulin compared with conventional treatment and risk of complications in patients with type 2 diabetes (UKPDS 33). UK prospective diabetes study (UKPDS) group. Lancet. 1998;352(9131):837-853.

6. Lachin JM, Orchard TJ, Nathan DM, DCCT/EDIC Research Group. Update on cardiovascular outcomes at 30 years of the diabetes control and complications trial/epidemiology of diabetes interventions and complications study. Diabetes Care. 2014;37(1):39-43.

7. Nathan D, DCCT/EDIC Research Group. The diabetes control and complications trial/epidemiology of diabetes interventions and complications study at 30 years: Overview. nathan DM; DCCT/EDIC research group. Diabetes Care. 2014;37(1):9-16.

8. Powers MA, Bardsley J, Cypress M, et al. Diabetes self-management education and support in type 2 diabetes. Diabetes Educ. 2017;43(1):40-53. 
9. Haas L, Maryniuk M, Beck J, et al. National standards for diabetes self-management education and support. Diabetes Care. 2014;37 Suppl 1:S144-53.

10. American Diabetes Association. American diabetes association standards of medical care in diabetes - 2017. Diabetes Care. 2017;40(Supplement 1):S1-S135.

11. American Association of Diabetes Educators (AADE). Role of the diabetes educator in inpatient diabetes management. Diabetes Educ. 2017;43(1):28-33.

12. Chrvala CA, Sherr D, Lipman RD. Diabetes self-management education for adults with type 2 diabetes mellitus: A systematic review of the effect on glycemic control. Patient Educ Couns. 2016;99(6):926-943.

13. Cooke D, Bond R, Lawton J, et al. Structured type 1 diabetes education delivered within routine care: Impact on glycemic control and diabetes-specific quality of life. Diabetes Care. 2013;36(2):270-272.

14. Robbins JM, Thatcher GE, Webb DA, Valdmanis VG. Nutritionist visits, diabetes classes, and hospitalization rates and charges: The urban diabetes study. Diabetes Care. 2008;31(4):655-660.

15. Shrader S, Kavanagh K, Thompson A. A diabetes self-management education class taught by pharmacy students. Am J Pharm Educ. 2012;76(1):13.

16. Westberg SM, Bumgardner MA, Brown MC, Frueh J. Impact of an elective diabetes course on student pharmacists' skills and attitudes. Am J Pharm Educ. 2010;74(3):49.

17. Morello CM, Neighbors M, Luu L, Kobayashi S, Mutrux B, Best BM. Impact of a first-year student pharmacist diabetes self-care education program. Am J Pharm Educ. 2013;77(10):215.

18. Wongwiwatthananukit S, Zeszotarski $\mathrm{P}$, Thai $\mathrm{A}$, et al. A training program for pharmacy students on providing diabetes care. Am J Pharm Educ. 2013;77(7):153. 
19. Accreditation Council for Pharmacy Education (ACPE). Accreditation standards and key elements for the professional program in pharmacy leading to a doctor of pharmacy degree ("standards 2016"). Chicago, IL: Accreditation Council for Pharmacy Education; 2015:31.

20. Fazel MT, Fazel M, Bedrossian NL, Picazo F, Pendergrass ML. A student-implemented elective to improve medical student confidence in providing diabetes self-management support. Adv Med Educ Pract. 2016;7:567-570.

21. Interprofessional Education Collaborative. Core competencies for interprofessional collaborative practice: 2016 update. Washington, DC.: Interprofessional Education Collaborative; 2016.

22. Health Professions Networks Nursing \& Midwifery Human Resources for Health. Framework for action on interprofessional education \& collaborative practice. $\mathrm{CH}-1211$ Geneva 27, Swirtzerland: WHO; 2010:64. http://www.who.int/hrh/resources/framework action/en/. Accessed July 8, 2017. 
Table 1. Pharmacy Student responses to Pre-and Post-Course Surveys for Diabetes Enrichment Elective ( $\mathrm{N}=10)$

\begin{tabular}{|c|c|c|c|c|c|c|c|c|c|c|c|c|c|}
\hline \multirow[t]{2}{*}{ Questions } & \multicolumn{6}{|c|}{ Pre-Course (n) } & \multicolumn{6}{|c|}{ Post-Course (n) } & \multirow[b]{2}{*}{$\begin{array}{c}\mathrm{p}- \\
\text { value }\end{array}$} \\
\hline & $\begin{array}{l}\text { Very } \\
\text { Low }\end{array}$ & Low & Moderate & High & $\begin{array}{l}\text { Very } \\
\text { High }\end{array}$ & $\begin{array}{l}\text { Median } \\
\text { (range) }\end{array}$ & $\begin{array}{l}\text { Very } \\
\text { Low }\end{array}$ & Low & Moderate & High & $\begin{array}{l}\text { Very } \\
\text { High }\end{array}$ & $\begin{array}{l}\text { Median } \\
\text { (range) }\end{array}$ & \\
\hline $\begin{array}{l}\text { 1. How would you describe your } \\
\text { confidence level in assessing } \\
\text { patients' understanding of } \\
\text { diabetes?* }\end{array}$ & 0 & 2 & 5 & 3 & 0 & $\begin{array}{c}3 \\
(2-4)\end{array}$ & 0 & 1 & 0 & 9 & 0 & $\begin{array}{c}4 \\
(2-4)\end{array}$ & 0.031 \\
\hline $\begin{array}{l}\text { 2. How would you describe your } \\
\text { confidence level in talking to } \\
\text { patients about diabetes? }\end{array}$ & 0 & 3 & 0 & 4 & 3 & $\begin{array}{c}3 \\
(2-4)\end{array}$ & 0 & 1 & 0 & 2 & 7 & $\begin{array}{c}4 \\
(2-4)\end{array}$ & 0.063 \\
\hline $\begin{array}{l}\text { 3. How would you describe your } \\
\text { confidence level in discussing } \\
\text { monitoring/ } \\
\text { managing blood glucose with } \\
\text { patients?* }\end{array}$ & 0 & 2 & 7 & 1 & 0 & $\begin{array}{c}3 \\
(2-4)\end{array}$ & 0 & 1 & 3 & 6 & 0 & $\begin{array}{c}4 \\
(2-4)\end{array}$ & 0.031 \\
\hline $\begin{array}{l}\text { 4. How would you describe your } \\
\text { confidence level in discussing } \\
\text { lifestyle modifications with patients } \\
\text { with diabetes?* }\end{array}$ & 0 & 1 & 5 & 4 & 0 & $\begin{array}{c}3 \\
(2-4)\end{array}$ & 0 & 1 & 1 & 3 & 5 & $\begin{array}{c}4.5 \\
(2-5)\end{array}$ & 0.031 \\
\hline $\begin{array}{l}\text { 5. How would you describe your } \\
\text { confidence level in discussing } \\
\text { diabetes self-management with } \\
\text { patients?* }\end{array}$ & 0 & 1 & 6 & 3 & 0 & $\begin{array}{c}3 \\
(2-4)\end{array}$ & 0 & 1 & 1 & 5 & 3 & $\begin{array}{c}4 \\
(2-5)\end{array}$ & 0.031 \\
\hline $\begin{array}{l}\text { 6. How would you describe your } \\
\text { confidence level in discussing the } \\
\text { basics of insulin pump therapy with } \\
\text { patients?* }\end{array}$ & 1 & 4 & 5 & 0 & 0 & $\begin{array}{c}2.5 \\
(1-3)\end{array}$ & 0 & 3 & 2 & 5 & 0 & $\begin{array}{c}3.5 \\
(2-4)\end{array}$ & 0.016 \\
\hline
\end{tabular}

*Item found to be statistically significant different between Pre- and Post-Course Survey when analyzed using a Wilcoxon Signed-Rank Test

$(P<.05)$ with a large effect size $(r>0.5)$. 